had increased to only $15 \%$ at 20 years. As would be expected, mortality is higher in infants with coexisting congenital heart disease than in those with isolated heart block. ${ }^{5}$ The causes of death are Stokes-Adams attacks or congestive cardiac failure.

Nevertheless, the asymptomatic infant with heart block still has a guarded prognosis even after the first year of life. In Esscher's series there was a $6 \%$ mortality between the ages of 6 months and 15 years and $18 \%$ of her patients required pacemakers because of syncopal attacks or heart failure. ${ }^{9}$ As patients reach adult life an increasing number develop symptoms and require pacemakers. ${ }^{311}$ The management of congenital complete heart block has improved enormously with the advent of small longlasting pacemaker generators-but there are still considerable technical problems in permanent pacing in small children. ${ }^{12}$ Pacing is mandatory in the presence of Stokes-Adams attacks or heart failure and may improve exercise tolerance if this is limited by a slow heart rate. Many patients with congenital heart block, however, can increase their ventricular rate satisfactorily on exercise and so remain asymptomatic. Can we identify which of them is at risk of sudden death?

Most authors suggest that the likelihood of symptoms is inversely related to the ventricular rate. All the patients who died in the neonatal period in one study had a rate below 60 a minute, ${ }^{9}$ and the mean ventricular rate in other series was lower in patients with symptoms than those without, in both childhood and adult life. ${ }^{71}$ Ambulatory electrocardiographic monitoring has shown episodes of profound ventricular slowing at night, ${ }^{8}$ though the prognostic relevance of this is unknown. Location of the site of the block by intracardiac recording was of no help in predicting the risk of syncope, though block in or distal to the bundle of His was associated with a slower ventricular rate than proximal block. ${ }^{7}$

Molthan et $a l^{13}$ described three deaths in patients with widening of the QRS complex and QT interval; two had episodes of ventricular tachycardia or fibrillation as well as ventricular standstill. Esscher ${ }^{9}$ observed a corrected QT interval of over 0.44 second in $84 \%$ of patients with symptoms. Patients with congenital heart block have a higher incidence of ventricular ectopic activity on exercise than controls, the incidence being particularly high in those with QRS widening. ${ }^{14}$ These results raise the possibility that some of the sudden deaths in patients with congenital heart block arise from ventricular tachyarrhythmias rather than asystole.

At present, then, permanent pacing is indicated for patients with congenital complete heart block if they have episodes of syncope, dizziness, heart failure, or impaired effort tolerance. The remainder need careful lifelong follow up. Future studies may show the need for prophylactic pacing in asymptomatic patients with a slow ventricular rate or a prolonged QRS or $\mathrm{QT}_{\mathrm{c}}$ interval.

S M COBBE

Clinical Reader and Honorary Consultant Cardiologist,

Cardiac Department,

John Radcliffe Hospital,

Oxford OX43 9DU

${ }^{1}$ Yater WM. Congenital heart-block-review of the literature; report of a case with incomplete heterotaxy; the electrocardiogram in dextrocardia. Am $\mathcal{F}$ Dis Child 1929;38:112-36.

${ }^{2}$ Michäelsson M, Engle MA. Congenital complete heart block: an international study of the natural history. Cardiovasc Clin 1972;4:85-101.

${ }^{3}$ Reid JM, Coleman EN, Doig W. Complete congenital heart block. Report of 35 cases. Br Heart $\mathcal{F} 1982 ; 48: 236-9$.

${ }^{4}$ Keith JD, Rowe RD, Vlad P. Heart disease in infancy and childhood. 3rd ed. New York: Macmillan, 1978:290-2.

${ }^{5}$ Pinsky WP, Gillette PC, Carson A Jr, McNamara DG. Diagnosis, management, and long-term results of patients with congenital complete atrioventricular block. Pediatrics 1982;69:728-33.
${ }^{6}$ Lev M. Pathogenesis of congenital atrioventricular block. Prog Cardiovaso Dis $1972 ; 15: 145-58$.

${ }^{7}$ Karpawich PP, Gillette PC, Garson A Jr, Hesslein PS, Porter CMcNamara DG. Congenital complete atrioventricular block: clinica and electrophysiologic predictors of need for pacemaker insertion. Am f Cardiol $1981 ; 48: 1098-102$.

${ }^{8}$ Levy AM, Camm AJ, Keane JF. Multiple arrhythmias detected durim nocturnal monitoring in patients with congenital complete heart block Circulation 1977;55:247-53.

${ }^{9}$ Esscher E. Congenital complete heart block. Acta Paediatr Scand $198 \%$ 70:131-6. (Review article.)

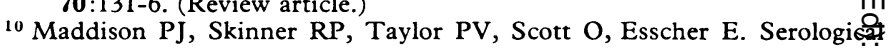
studies in congenital heart block. Br Heart $\mathcal{f}$ (in press). (Abstract.)

11 Esscher EB. Congenital complete heart block in adolescence and adult lifo A follow-up study. Eur Heart $\mathcal{F} 1981 ; 2: 281-8$.

12 Hayward R, Somerville J, Rickards AF. Problems of permanent pace. making in children. PACE 1979;2:A872.

${ }^{13}$ Molthan ME, Miller RA, Hastreiter AR, Paul MH. Congenital hea block with fatal Adams-Stokes attacks in childhood. Pediatrics 196 30:32-41.

14 Winkler RB, Freed MD, Nadas AS. Exercise-induced ventricular ectopy in children and young adults with complete heart block. Am Heart $₹$ $1980 ; 99: 87-92$.

\section{The sticky eyed infant}

A sticky eyed infant will worry his parents and should concerin his doctor-for prompt and appropriate treatment is called foN

Conjunctivitis in the neonate presents with redness, dis charge, and sometimes watering; the condition is known ophthalmia neonatorum and was once a major cause of neonatgl blindness in the West. ${ }^{1}$ The severe corneal damage caused infection with Neisseria gonorrhoeae led to the use of the Credé prophylaxis with silver nitrate drops, and this reduced the rage of ophthalmia neonatorum in infants born to infected mothers to less than $2 \%{ }^{2}$ For many years now most European countries and much of the United States of America, however, ham abandoned the use of routine prophylaxis, because of the occurrence of chemical conjunctivitis from the silver nitrage drops themselves and the introduction of reliable diagnostif facilities. ${ }^{3}$

Nevertheless, ophthalmia neonatorum remains common Culture of the discharge may allow a specific diagnosis to made. $N$ gonorrhoeae, Staphylococcus aureus, Streptococc viridans, and Haemophilus spp are established bacterial path gens, but in recent years Chlamydia trachomatis is being detect more frequently ${ }^{4}$ and accounts for many of the infections re sistant to chloramphenicol. Material from a conjunctival swa should be examined with a Gram stain and cultured for both bacterial and viral pathogens in all severe cases, all those whe the mother is known to be infected, in the presence of arf corneal damage, or in infants who have not responded to treat ment. Probably the most effective antibiotic to use initially $\underline{\underline{T}}$ $1 \%$ chloramphenicol ointment given six times daily; in patieng shown to have infection with chlamydia tetracycline ointme may be given to the baby ${ }^{5}$ while his mother is treated wi erythromycin.

The second common cause of a watering eye in a baby $\frac{2}{85}$ obstruction of the nasolacrimal duct, which occurs in nearty half of all newborn babies but causes symptoms in very few The affected eye waters, especially in the cold or wind, and $\stackrel{0}{\Phi}$ prone to infections, often by organisms of low pathogenicit\$. Sometimes a mucocele of the lacrimal sac develops or may present at birth ${ }^{7}$; it may be detected by firm but gentle pressufe medial to and below the inner canthus, which will express mucus or pus into the conjunctival sac. The obstruction to the nasolacrimal system is usually at the lower end of the nas lacrimal duct and is a result of incomplete development. ${ }^{8}$ 
Usually the signs and symptoms resolve spontaneously in the first few weeks or months and expectant management should be the rule. Massage over the lacrimal sac will raise its hydrostatic pressure and the parent should be instructed in gentle but firm massage from above the inner canthus downwards along the base of the nose. If the discharge becomes excessive a circumscribed course of antibiotic eye ointment should be given, preferably after culture of the discharge. The decision whether or not to syringe and probe the nasolacrimal duct is based on the severity of the watering and discharge, the length of time that has been allowed for spontaneous resolution, and the general health of the baby. As much time as possible should be allowed for spontaneous resolution-even up to a year-provided that the symptoms are not severe. Most British ophthalmologists prefer to carry out the operation under general anaesthesia, but it can be done without anaesthetic in smaller babies. Probing is successful in over $90 \%$ of patients with simple membranous obstruction of the distal end of the nasolacrimal duct, ${ }^{9}$ but is less successful in patients with obstruction at other sites, which are fortunately much rarer. Failure to respond to two separate probings may call for the use of a silicone tube attached to two stainless steel wires which are passed down the nasolacrimal duct. The tubing is left in the duct for a few weeks, tied with a suture in the nose to prevent its loss. ${ }^{10} \mathrm{With}$ appropriate early treatment and care and gentleness in any surgical manoeuvres more extensive surgery is now rarely needed in childhood for congenital nasolacrimal duct obstruction.

Consultant Ophthalmic Surgeon,

DAVID TAYLOR

Hospital for Sick Children,

Great Ormond Street,

London WC1N 3JH

1 Smith CA, Halse L. Ophthalmia neonatorum. Public Health Rep 1955; 70:462-70.

2 Armstrong JH, Zacarias F, Rein MF. Ophthalmia neonatorum: a chart review. Pediatrics 1976;57:884-92.

${ }^{3}$ Wahlberg V. Reconsideration of Credé prophylaxis. A study of maternity and neonatal care. Acta Paediatr Scand 1982;suppl 295:1-73.

4 Pierce JM, Ward ME, Seal DV. Ophthalmia neonatorum in the $1980 \mathrm{~s}$ : incidence, aetiology and treatment. Br $\mathcal{f}$ Ophthalmol $1982 ; 66: 728-31$.

${ }^{5}$ Patamasucon P, Rettig PJ, Faust KL, Kusmiesz HT, Nelson JD. Oral v topical erythromycin therapies for chlamydial conjunctivitis. $A m \mathcal{F} D i$ Child 1982;136:817-21.

${ }^{6}$ Korchmáros I, Szalay E. Cannula-probing combined with nasal procedure for dacryocystitis neonatorum. Acta Ophthalmol 1978;56:357-62.

- Weinstein GS, Biglan AW, Patterson JH. Congenital lacrimal sac mucoceles. Am $\mathcal{F}$ Ophthalmol 1982;94:106-10.

"Sevel D. Development and congenital abnormalities of the nasolacrimal apparatus. F Pediatr Ophthalmol Strabismus 1981;18:13-9.

${ }^{9}$ Kushner BJ. Congenital nasolacrimal system obstruction. Arch Ophthalmol $1982 ; 100: 597-600$.

1" Kraft SP, Crawford JS. Silicone tube intubation in disorders of the lacrimal system in children. Am $\mathcal{F}$ Ophthalmol 1982;94:290-9.

\section{Medical manpower information}

A former senior administrative medical officer who wanted to telephone one of his clinical colleagues was said to refer to a file in his office which told him where any consultant in his region would be at any time on any day of the week. How often he turned out to be misinformed is not on record. Yet consultants are easy game for a medical manpower information system, compared with senior house officers and registrars. With junior doctors the problem is several stages further back than knowing where they are at a given time. Indeed, before knowing who a registrar or senior house officer is, in terms of age, sex, where he comes from, how long he has been in post, and where he intends to go, there is the simple question of which doctor is occupying which job; and even this presupposes reliable information about exactly what jobs exist.

The disadvantages of not having better information about medical staff have been acutely apparent to those concerned with postgraduate training and were clearly seen by the House of Commons Select Committee. ${ }^{1}$ Twelve years ago one postgraduate dean set up an "operations room" with a wall chart purporting to describe the occupant of every junior hospital post in his region; he found that he needed a full time secretary to try to keep the information up to date, and the attempt was not a complete success. More recently, the postgraduate dean's office of the South West Thames region has pioneered a computer based information system for junior hospital posts and their occupants-a notable achievement, but the constant updating of any independent system of this kind must prove expensive in time and effort. Some other regions-all too conscious of their need-have begun to develop systems along the same lines as South West Thames but with variations of style and management. In fact, style and management are everything, for the way in which the potential usefulness or meddlesomeness of a data system is perceived, and the practicability of running it, will certainly determine its success.

In principle, the National Health Service coding system for regions and districts and for specialties and subspecialties can be used as the basis for a system of identification and coding of hospital posts. Some years ago the Council for Postgraduate Medical Education proposed such a coding system. There were untidy problems around the edges concerning part time and other supernumerary appointments, university posts with NHS grading, secondments, and rotational training programmes, but these are not insuperable. The proposals were discussed but not implemented. Meanwhile, the Royal College of Physicians has devised its own code numbers for posts recognised for training by the college and the Joint Committee on Higher Medical Training, and some other colleges are developing computer based information systems for their own specialties.

At the request of the Chief Medical Officer, $\mathrm{Mr} \mathrm{J} \mathrm{C} \mathrm{C}$ Smith, formerly of the Department of Health and Social Security and now with the Nuffield Provincial Hospitals Trust, produced constructive suggestions for setting up a medical manpower information system which would be based at regional and district level. The mutual compatibility of these regional and district systems would make it possible to construct a national data base for medical manpower, and the DHSS would be an obvious customer for this information. John Smith's proposals were warmly welcomed, not least by postgraduate deans. The compilation of three sets of information was envisaged: about posts, people in posts, and the history of those who had previously occupied each post. In addition to these recommendations John Smith's report contained a brilliantly written analysis of the problems of the career structure and the consequent need for better data, which deserved to be very widely read.

Hopes that an integrated NHS/DHSS system can be developed have been raised by the report of the Körner Working Group $\mathrm{E}$ on manpower information. ${ }^{2}$ The recommendations are very much in line with John Smith's but at a less ambitious level. In other words, the attempt has been made to define a sensible and practicable minimum set of data which could be compiled at district and regional level 